\title{
GRUPO DE PESQUISA: PERSPECTIVA ECOLOGISTA DE EDUCAÇÃO
}

Marcos Reigota ${ }^{1}$

Resumo. Neste artigo, apresentamos a origem e os principais momentos da história do Grupo de Pesquisa Perspectiva Ecologista de Educação, da Universidade de Sorocaba, assim como as redes de cooperação científica no Brasil e no exterior e suas bases teóricas e metodológicas, situando-o com a dimensão política do cotidiano escolar e na corrente pós-moderna de educação. Apresentamos também as dissertações concluídas e algumas das referências bibliográficas que têm sido utilizadas desde 1998.

Palavras-chave: Cotidiano Escolar, Ecologista, Estudos Culturais, Pós-moderna.

Abstract: In this paper, we present the origins and some of the most important historical moments of the Ecological Approach to Education Research Group, of the University of Sorocaba, as well as its scientific cooperation networks in Brazil and abroad, its theoretical and methodological approaches, and its connections with the political dimension of everyday school life and the postmodern trends in education. In addition, we present some dissertations and a selected bibliography that has been used by the group since 1998 .

Keywords: Everyday School Life, Ecological, Cultural Studies, Postmodern.

\section{Histórico}

O grupo teve inicio em 1998, quando ingressei no Programa de Pósgraduação em Educação da Universidade de Sorocaba. Nesse período estava ocorrendo significativas mudanças na Teoria das Representações Sociais e o grupo se articulou inicialmente para discutir essas mudanças e a sua aproximação com os Estudos Culturais. A temática ambiental foi sendo inserida com a colaboração de vários colegas, principalmente da PUC-SP e da USP- São Carlos. Nesse período inicial foi de fundamental importância a contribuição do professor Newton Aquiles Von Zuben ( que trabalhava no PPGE da Uniso no mesmo período) e o

\footnotetext{
${ }^{1}$ Programa de Pós-Graduação em Educação da Universidade de Sorocaba
} 
seu aporte teórico relacionado com a bioética e com as tecnociências. Sua contribuição filosófica e pedagógica estimulou o grupo a se aprofundar nas contribuições de Gilbert Hottois, Martin Buber e Jean Ladriére (que havia sido professor dele e meu na Universidade Católica de Louvain).

Depois de várias modificações no Programa de Pós-graduação em Educação da Uniso, que acarretou na consolidação da linha de pesquisa sobre cotidiano escolar (muito bem avaliada por Demerval Saviani) nosso grupo passou a navegar por águas mais tranqüilas. Um outro aspecto importante foi a relação que estabelecemos e aprofundamos com o GT Cotidiano e Práticas Sociais da Anpepp( Associação Nacional de Pesquisa em Psicologia) fundado e liderado pela professora da PUC-SP, Mary Jane Paris Spink.

Nosso grupo adotou a denominação Perspectiva Ecologista de Educação em 2000 após a publicação dos meus livros "Ecologista" (1999) e " a Floresta e a escola: Por uma educação ambiental pós-moderna" (1999) e após a pesquisa realizada no Japão, com bolsa da Fundação Japão, sobre a memória das bombas lançadas pelos EUA sobre a população civil de Hiroshima e Nagasaki, na cultura, na educação e no cotidiano japonês. Os livros citados ( e outros livros e artigos do período de 1998 a 2000) e a pesquisa no Japão foram fundamentais para que o grupo redefinisse suas prioridades teóricas e metodológicas, assim como para estabelecer as relações da educação ambiental com o cotidiano escolar e viceversa. Nesse sentido priorizamos a abordagem teórica pautada nas contribuições dos Estudos Culturais e as suas relações com o cotidiano escolar.

Entre os autores iniciais que permaneceram como referências básicas estão Félix Guattari, Serge Moscovici , Gianni Vattimo e Cornelius Castoriadis. No que diz respeito ao cotidiano (e às práticas sociais) destacamos nosso diálogo com o grupo da Anpepp (Cotidiano e Práticas Sociais) e principalmente com Mary Jane Paris Spink (PUCSP) Peter Spink(FGV), Solange Jobin (PUC_RJ e UERJ), Neuza de Fátima Guareschi (UFRGS), Benedito Medrado (UFPE), Henrique Caetano Nardi (UFRGS) e Maria Auxiliadora Teixeira Ribeiro (UFAl).

Nos aspectos pedagógicos os autores com os quais temos dialogado são Nilda Alves, Regina Leite Garcia, Silvio Gallo, Inês Barbosa de Oliveira, Newton Aquiles Von Zuben, Ana Maria Araújo Freire, Ivani Catarina Fazenda, Guacira Louro e Jean-Marie De Ketele. Dos autores específicos da educação ambiental cito os que nos últimos três anos temos tido um diálogo mais constante (apesar das diferenças epistemológicas de cada um). São eles e elas: Leandro Belinaso Guimarães, Maria Cecília Focesi Pelicioni, Ana Godoy, Ana Maria Prevê, Andréa Pelicioni, Jara Fontoura, Sandro Sayão, Valdo Barcelos, Maria do Carmo Galiazzi, Maria Inês Higuchi, Nilson Moulin, Neila Guimarães, Rosa Maria Feiteiro Cavalari, Andréia Marin, Vera Rodrigues, Arleude Bortolozzi, Clarice Sumi e Marilia Tozzoni-Reis. No plano internacional nosso diálogo tem se dado com Silvia Zaccaria e Elisabetta Falchetti (Itália), Pedro Verga Marcote e Pablo Meira (Espanha), Edgar Gonzalez- Gaudiano ( México), Lucie Sauvé e Isabel Orellana (Canadá), Alberto Arenas (EUA), Christine Partoune e Isabel Yepez (Bélgica), 
André Giordan (Suiça), Olga Bermudez (Colômbia) e Masato Morita (Japão).

\section{Problemas, questões de pesquisas e objetivos gerais das investigações}

A-)A educação ambiental definida como educação política pode ser entendida como uma filosofia da educação e colaborar com os projetos políticos e pedagógicos das práticas cotidianas?

B-) Como que as práticas pedagógicas cotidianas que não reivindicam a denominação de educação ambiental podem contribuir com a ampliação e definição da perspectiva ecologista de educação?

C-) Como que nossas práticas sociais colaboram para que se (re) defina o compromisso político das práticas pedagógicas que se identificam como educação ambiental?

D-)A educação ambiental definida como educação política pode contribuir parar a desconstrução de práticas sociais e pedagógicas autoritárias, injustas e ecologicamente insustentáveis?

\section{Referenciais teóricos e metodológicos que tem orientado as pesquisa do grupo}

Como referencial e cultural o grupo está situado na corrente pós-moderna de educação, o que permite utilizar como possibilidades metodológicas a etnografia, as narrativas ficcionais, as biografias e produtos culturais diversos (filmes, literatura, artes plásticas, música, arte pop). Entre os trabalhos produzidos incluo, as dissertações relacionadas de forma específica com a educação ambiental e que estão presentes no livro Perspectiva Ecologista de educação, organizado por Rodrigo Barchi e por mim e que se encontra no prelo:

Perspectiva ecologista de educação: sua presença na vida cotidiana - Marcos Reigota e Rodrigo Barchi

\section{Uma viagem etnográfica - Leodir Ribeiro}

\section{A educação ambiental e a agricultura na bacia hidrográfica do rio Capivari} - Itapetininga/SP - Bárbara Heliodora Prado

Educação física e educação ambiental: uma possibilidade de diálogo através das práticas pedagógicas com crianças - Íris Adriane Santoro Cardoso

Ecologizar a educação infantil: fragmentos e narrativas do cotidiano da Creche Sabiá - Sorocaba/SP - Kátia Regina Pereira

Frans Krajcberg: Artista-educador - Adriana Lima

De contos de fadas à poética de Rubens Matuck: uma trajetória de representações sobre meio ambiente e educação - Maria Celina Barros Mercúrio Bonfanti..

Desconstruindo representações sobre meio ambiente e educação ambiental - Eneida Maria Molfi Goya

Formação e identidade dos/das educadores/educadoras ambientais Adilson Januário da Silva 
Diálogos com Bernardo e o homem-máquina - Antonio Almeida da Silva..

Políticas públicas e práticas pedagógicas: um estudo de caso dos PCN's Meio ambiente - Luis Roberto Rodrigues de Mattos

A biodiversidade redefine a formação do/da farmacêutico(a)? - Daiana Tobias Nunes

Dando um rolê, tomando um ar fresco: as pichações e a perspectiva ecologista de educação - Rodrigo Barchi

\section{Referencias teóricas que se encontram nos trabalhos acima citados}

ALVES, N. e GARCIA, R. L.(Org.). Como o nosso corpo passa a ser o de professora. In: GARCIA, Regina L. (Org.) O corpo que fala dentro e fora da escola. Rio de Janeiro: DP\&A, 2002.

BARBOSA, I. Alternativas emancipatórias do currículo. São Paulo: Cortez, 2004.

BARCELOS, V. H. L. As questões ambientais, a educação e as representações sociais em diálogo necessário. In; Jornada Internacional sobre Representações Sociais: Teorias e Campos de Aplicação. Natal: Universidade do Rio Grande do Norte, 1998.

BARCHI, R. Pichar, pixar, grafitar, colar: os discursos e representações sobre as pichações nas escolas analisados nas perspectivas ambiental e libertária. Revista Teias. Rio de Janeiro: n. 15-16, v. 8, 2007.

BARROS, Manoel de. O livro sobre o nada. $3^{\text {a }}$ ed. Rio de Janeiro, Record, 2001.

BENJAMIN, W. A criança, o brinquedo e a educação. São Paulo: Summus, 1984.

BEY, H. TAZ: Zona Autônoma Temporária. São Paulo: Conrad, 2001.

CASTORIADIS, C. Uma sociedade à deriva: entrevistas e debates, 1974-1997. Edição organizada por Enrique Escobar, Myrto Gondicas e Pascal Vernay; [tradução Cláudia Berliner]. Aparecida, SP: Idéias e Letras, 2006. 310 p.

DA MATTA, R. A casa e a rua: cidadania, mulher e morte no Brasil. Rio de Janeiro: Rocco. 1997

DELEUZE, G. Lógica do sentido. São Paulo: Perspectiva, 2006.

FADIGAS, N. Inverter a educação: De Gilles Deleuze à Filosofia da Educação. Porto: Porto Editora, 2003.

FREIRE, P. Pedagogia da Autonomia: saberes necessários a prática educativa. 28. ed. São Paulo: Paz e Terra, 1996.

GALLO, S._Deleuze e a Educação. Belo Horizonte: Autêntica, 2003.

GODOY, A. A menor das ecologias. São Paulo: Edusp, 2008.

GOERGEN, P. Pós Modernidade, ética e educação. $2^{\mathrm{a}}$ ed. revista - Campinas, SP: Autores Associados, 2005. 
GUATTARI, F. As três ecologias. Campinas: Papirus, 1991.

HALL, S. A identidade cultural na pós-modernidade. $5^{\mathrm{a}}$.ed. Rio de Janeiro: DP\&A. 2001

HOME, S. Assalto à Cultura: utopia, subversão, guerrilha na (anti)arte do século XX. São Paulo: Conrad, 1999.

KRAJCBERG, F. A natureza de Krajcberg. Rio de Janeiro: GB Arte. 2005.

LUTZENBERGER, J. Fim do futuro? Manifesto Ecológico Brasileiro. Porto Alegre: Movimento, Universidade Federal do Rio Grande do Sul, 1980.

MOSCOVICI. S. A representação social da psicanálise. Rio de Janeiro: Zahar, 1994.

OLIVEIRA, I. B. Alternativas emancipatórias em currículo. São Paulo: Cortez, 2004.

ONFRAY, M. A política do rebelde: tratado de insubmissão e resistência. São Paulo: Record, 2001, tradução de Mauro Pinheiro.

PELICIONI, M. C. F. Educação em saúde e educação ambiental: estratégias de construção da escola promotora de saúde. Tese (Livre Docência) UNIVERSIDADE DE SÃO PAULO, São Paulo, 2000.

PRIGOGINE, Ilya; STENGERS, Isabelle. A Nova Aliança. Brasília, Editora Universidade de Brasília, 1997.

RODRIGUES, V. Muda o mundo, Raimundo: educação ambiental no ensino básico do Brasil. Brasília: WWF, 1997.

SANTOS, B. S. Introdução a uma ciência pós-moderna. Rio de Janeiro: Graal, 1989.

SPINK. M. J. O conhecimento no cotidiano: as representações sociais na perspectiva da psicologia social. São Paulo: Brasiliense, 1995.

TOZONI-REIS, M.F. de C. Educação ambiental: natureza, razão e história. Campinas: Autores Associados, 2004.

TURCHI, Maria Zaira. Literatura e Antropologia no Imaginário. Brasília: Editora da UnB, 2003.

VATTIMO, G. O fim da modernidade: niilismo e hermenêutica na cultura pósmoderna. São Paulo: Martins Fontes, 1996.

ZUBEN, Newton Aquiles Von. Bioética e tecnociências: a saga de Prometeu e a esperança paradoxal. Bauru, SP, Edusc, 2006.

Artigo recebido em 20/08/2010 _ aprovado em 17/12/2010 